\title{
Influence of a Multidisciplinary Program of Diet, Exercise, and Mindfulness on the Quality of Life of Stage IIA-IIB Breast Cancer Survivors
}

Integrative Cancer Therapies

Volume 19: I-II

(C) The Author(s) 2020

Article reuse guidelines:

sagepub.com/journals-permissions DOI: I0.I I77/I534735420924757

journals.sagepub.com/home/ict

(S)SAGE

\author{
Julia Ruiz-Vozmediano, MD'(D, Sarah Löhnchen², Lucas Jurado ${ }^{3}$, \\ Rosario Recio ${ }^{4}$, Andrea Rodríguez-Carrillo², Miriam López ${ }^{2}$, \\ Vicente Mustieles, $\mathrm{PhD}^{2,5}$, Manuela Expósito \\ Manuel Arroyo-Morales, MD, $\mathrm{PhD}^{4}$, and Mariana F. Fernández, $\mathrm{PhD}^{2,4,5}$
}

\begin{abstract}
Background: Integrative oncology has proven to be a useful approach to control cancer symptoms and improve the quality of life $(\mathrm{QoL})$ and overall health of patients, delivering integrated patient care at both physical and emotional levels. The objective of this randomized trial was to evaluate the effects of a triple intervention program on the QoL and lifestyle of women with breast cancer. Methods: Seventy-five survivors of stage IIA-IIB breast cancer were randomized into 2 groups. The intervention group (IG) received a 6-month dietary, exercise, and mindfulness program that was not offered to the control group (CG). Data were gathered at baseline and at 6 months postintervention on QoL and adherence to Mediterranean diet using clinical markers and validated questionnaires. Between-group differences at baseline and 3 months postintervention were analyzed using Student's $t$ test for related samples and the Wilcoxon and Mann-Whitney $U$ tests. Results: At 6 months postintervention, the IG showed significant improvements versus CG in physical functioning $(p=.027)$, role functioning $(p=.028)$, and Mediterranean diet adherence $(p=.02)$ and a significant reduction in body mass index $(p=.04)$ and weight $(p=.05)$, with a mean weight loss of $0.7 \mathrm{~kg}$ versus a gain of $0.55 \mathrm{~kg}$ by the CG $(p=.05)$. Dyspnea symptoms were also increased in the CG versus IG $(p=.066)$. Conclusions: These results demonstrate that an integrative dietary, physical activity, and mindfulness program enhances the QoL and healthy lifestyle of stage IIA-IIB breast cancer survivors. Cancer symptoms may be better managed by the implementation of multimodal rather than isolated interventions.
\end{abstract}

\section{Keywords}

integrative oncology, breast cancer, quality of life, diet, exercise, mindfulness

Submitted December 5, 2019; revised April I, 2020; accepted April 17, 2020

\section{Introduction}

The World Health Organization has estimated that modifiable risk factors are responsible for up to a third of cancer cases. Increasing attention is being given to primary prevention campaigns against cancer, and the European code against cancer includes 12 research-based recommendations to reduce its incidence of this disease. ${ }^{1-3}$ Despite these efforts, the incidence of cancer continues to increase every year. $^{4}$

Breast cancer $(\mathrm{BC})$ is the most frequent cancer among women worldwide and is the leading cause of cancer death among women in middle- and high-income countries. ${ }^{4}$ The earlier diagnosis of $\mathrm{BC}$ and improvements in its treatment have increased the $\mathrm{BC}$ survival rate. ${ }^{4}$ However, repercussions of the disease and its treatment are responsible for

\footnotetext{
I"Virgen de las Nieves" University Hospital, Granada, Spain 'University of Granada, Granada, Spain

${ }^{3}$ Mixed University Sport and Health Institute, Granada, Spain ${ }^{4}$ Instituto de Investigación Biosanitaria (ibs.GRANADA), Granada, Spain ${ }^{5}$ Consortium for Biomedical Research in Epidemiology \& Public Health (CIBERESP), Spain
}

\section{Corresponding Author:}

Mariana F. Fernández, Department of Radiology and Physical Medicine, University of Granada, Av. de la Investigación, II, Granada I8016, Spain. Email: marieta@ugr.es 
physical and neuropsychological symptoms that can impair the health-related quality of life $(\mathrm{QoL})$ of survivors over the medium and long term. ${ }^{5}$

The World Cancer Research Fund conducted a systematic review of epidemiological studies on women living with $\mathrm{BC}$, including those who recovered from the disease, examining the relationship of life style choices with the prognosis of patients, and the risk of recurrence in survivors; it highlighted the importance of a healthy body weight, the performance of physical exercise, and the consumption of a healthy diet. ${ }^{6}$ Specifically, the review recommended a diet with high fiber content, low fat (especially saturated fat) content, and a reduced consumption of meat and processed food products. This is similar to the Mediterranean $\operatorname{diet}(\mathrm{MD})$ pattern, ${ }^{7}$ which has been found to reduce the risk of BC, especially the most aggressive tumors, by up to $30 \%$ and to increase the likelihood of survival. $8,9,10$

The relationship between physical exercise and survival after a BC diagnosis was addressed in a recent meta-analysis that included 12108 women. ${ }^{11}$ It found that exercise reduced the risk of death from $\mathrm{BC}$ by $30 \%$ and of death from any cause by $41 \%$, percentages that rose to $50 \%$ and $64 \%$, respectively, for women with hormone receptor-positive tumors. ${ }^{11}$ Physical activity has also been reported to reduce the likelihood of recurrence and metastatic spread. ${ }^{12}$ Mechanisms underlying the effects of physical activity include the following: reductions in fasting glucose and insulin levels, insulin resistance, insulin-like growth factor- 1 secretion, and inflammatory parameters, and increases in Treg and NK cell counts. ${ }^{12}$ In addition, exercise can reduce oxidative stress and free radical damage by increasing antioxidant and adiponectin levels and decreasing leptin levels (by reducing adipose tissue mass). ${ }^{12}$

Psychological interventions have been found to improve the health of patients with $\mathrm{BC},{ }^{13,14}$ and meditation has been used as a complementary approach. ${ }^{15}$ It has been proposed that meditation can improve the immune system of patients, besides contributing to their emotional healing. ${ }^{16}$ Various randomized trials have supported the benefits of mindfulness interventions to reduce stress in $\mathrm{BC}$ patients and to improve their symptoms and QoL. ${ }^{17-19}$

The primary objective of the present trial was to evaluate whether a triple intervention program (nutrition, physical exercise, and mindfulness) after conventional treatment can improve the QoL, symptoms, and complications of patients with $\mathrm{BC}$ and promote their weight control and a healthy lifestyle.

\section{Methods}

\section{Participant Recruitment and Inclusion/Exclusion Criteria}

Participants were recruited from among women with stage IIA-IIB BC attended by the Oncology Mammary Unit of a level-3 hospital in Granada, Southern Spain (University Hospital "Virgen de las Nieves", HUVN), who had completed their cancer treatment more than 12 months earlier. Inclusion criteria were $(a)$ age $>18$ years; $(b)$ residence in the city or metropolitan area of Granada; $(c)$ absence of physical or psychological limitations impeding participation in the program; and $(d)$ no receipt of specific physical exercise or meditation training or advice from a nutrition specialist.

Before recruitment started, the study was approved by the Clinical Research Ethics Committees of the hospital and the Andalusian Biomedical Research Ethics Committee. At recruitment, the aims of the study were explained to potential participants, who all gave their written informed consent. The study complied with the principles of the Declaration of Helsinki and Spanish Legislation on Clinical Research (Decrees 561/1993 and 033/2004), and the protocol was registered at ClinicalTrials.gov (NCT04150484).

\section{Baseline Interview}

After providing written consent, the women attended an initial interview in which an ad hoc questionnaire was used to gather sociodemographic, lifestyle, and clinical data. These included the following: age, place of residence, type of housing, educational level, marital status, weight changes throughout life, present and previous occupations, self-perceived economic status, medical history, tobacco and alcohol consumption, hours of sleep, and physical activity, among others. The weight and height of participants were measured using a SECA electronic scale. Participants also completed the questionnaire of the European Organization for Research and Treatment of Cancer QLQ-C30 scale s,21 $^{20,21}$ to evaluate their QoL. This 30-item questionnaire has been widely used to assess the health-related QoL of cancer patients in international clinical trials. ${ }^{21}$ Items are grouped in 5 functional domains (physical [5 items], role [2 items], cognitive [2 items], emotional [4 items], and social [2 items]), 3 symptom domains (fatigue [3 items], pain [2 items], nausea and vomiting [2 items]), 1 global health QoL domain (2 items), and 6 single items (appetite loss, diarrhea, dyspnea, constipation, insomnia, financial impact). All domain/symptom scores were converted to scores ranging from 0 to 100 using the scoring manual. ${ }^{20}$ Higher scores for the functional and global QoL domains indicate better functioning and QoL, whereas higher scores for the symptom and single items indicate worse symptoms and conditions.

Participants also completed a validated semiquantitative 93-item Food Frequency Questionnaire (http://bibliodieta. umh.es/files/2011/07/CFA101.pdf) ${ }^{22}$ and a 24-hour dietary recall questionnaire. A 14-item Mediterranean diet adherence questionnaire, which excluded alcohol consumption, ${ }^{23,24}$ was administered in a face-to-face interview.

Participants were then given an appointment a few days later (beginning of January 2016) to provide a fasting blood 
sample at the Oncology Mammary Unit of the hospital for analysis of glucose, triglycerides, and cholesterol levels $(\mathrm{mg} / \mathrm{dL})$, and tumor markers (carcinoembryonic antigen [CEA] and cancer antigen [CA 15.3]), and a full blood count.

\section{Randomization}

Eligible participants were allocated 1:1 to the intervention group (IG) or control group (CG) in an nonmasked stratified manner using a computerized minimized-randomization procedure with the $\mathrm{R}$ program and by an independent statistician blinded to intervention allocation throughout the study, obtaining 2 groups that were similar in age, tumor stage, tumor hormone receptor status (estrogen receptor and her2 status), and hormone treatment.

\section{Intervention Program}

Women in the IG received a 6-month program on dietary habits, physical activity, and mindfulness. They were asked to keep the contents of the course confidential until the end of the follow-up period.

Dietary Intervention. In February 2016, the IG took part in three 5-hour workshops on healthy eating patterns for the general population and cancer patients and received information on risk factors for $\mathrm{BC}$ and on preventive factors, including the recommendations of the European Code Against Cancer, the benefits of the MD, and the control of weight and energy intake. The workshops emphasized the positive effects of certain foods and food groups (fruits, vegetables, nuts, grains, legumes, fish, dairy products, etc) and the negative effects of others (red/processed meats, high-fat products, etc). Recommendations were given on hydration and drinks to be avoided (sugary and alcoholic) and on the reduction of salt and the use of spices. Other related information included ideas for healthy food preparation and grocery shopping, among others. At the end of the workshop, the women received a leaflet with a summary of the information received and a chart giving flexible dietary options for a 2-week period.

A second "refresher" workshop was held after a 2-month interval, repeating and discussing the main points in the first workshop, addressing doubts and questions. A third meeting was then organized, to which each participant described a healthy menu consisting of a starter, main course, and dessert, and passed on the recipes for the dishes. Besides the sharing of recipes, the aim of this last workshop was to familiarize the women with unknown healthy foods and cooking methods.

Physical Activity Intervention. During a 7-week period (MarchApril 2016), women in the IG attended a 60-minute class 3 times per week at the "Cuídate" Support and Research Unit for Oncology Patients. It was run by physiotherapists and health care professionals from the School of Health Sciences (University of Granada). The classes included core, upper limb, and lower limb exercises, targeted stretching sessions focused on the upper limbs and, once a week, Spanish dancing (Sevillanas and Flamenco). Each exercise session started with a 10-minute warm-up (games, walking fast, etc), followed by a 30-minute period of exercise circuits for different areas of the body, performing each exercise 6 to 8 times, and repeating each circuit 3 times, and it ended with a 10-minute cool-down period of targeted stretching. The weekly dance class started with a 10-minute warm-up (mobilization of ankles, knees, hips, shoulders, and head), followed by a 30-minute period to learn the positions and movements required for dancing Sevillanas and Flamenco.

Mindfulness Intervention. During a 4-week period (May 2016), the women in the IG attended a twice-weekly 90-minute mindfulness-based stress reduction (MBSR) session, supervised by an MBSR-trained psychologist involved in the research project. The program was a slight modification of a previously published 8-week MBSR program ${ }^{25}$ focused on the practice of mindfulness through meditation and yoga.

\section{Follow-up of Breast Cancer Women}

A follow-up of all participants (IG and CG) was conducted at 6 months after the end of the intervention, measuring their weight, QoL, Mediterranean Diet adherence questionnaire, and blood parameters using the same procedures as at baseline. Two main study outcomes were considered: the change between baseline and follow-up in QoL (functional and symptom scales) and complications; and the change in weight, healthy lifestyle habits, and blood parameters. For ethical reasons, the CG received the same intervention program after the follow-up period.

\section{Statistical Analysis}

The sample size was estimated to achieve a power of $80 \%$ to detect a significant postintervention improvement in EORTC QLQ-C30 functional scores $(p<.05)$, based on a previous study, ${ }^{26}$ calculating a minimum number of 36 women in each study group. The sample size was increased to 45 women per group to allow for possible dropouts.

In a descriptive statistical analysis, mean (standard deviation), and median (25 and 75 percentiles) values were calculated for quantitative variables and percentages for qualitative variables. Student's $t$, Wilcoxon, and/or MannWhitney $U$ tests were used for between-group comparisons in baseline demographics, QoL, and clinical characteristics, and the nonparametric Wilcoxon test for comparisons 


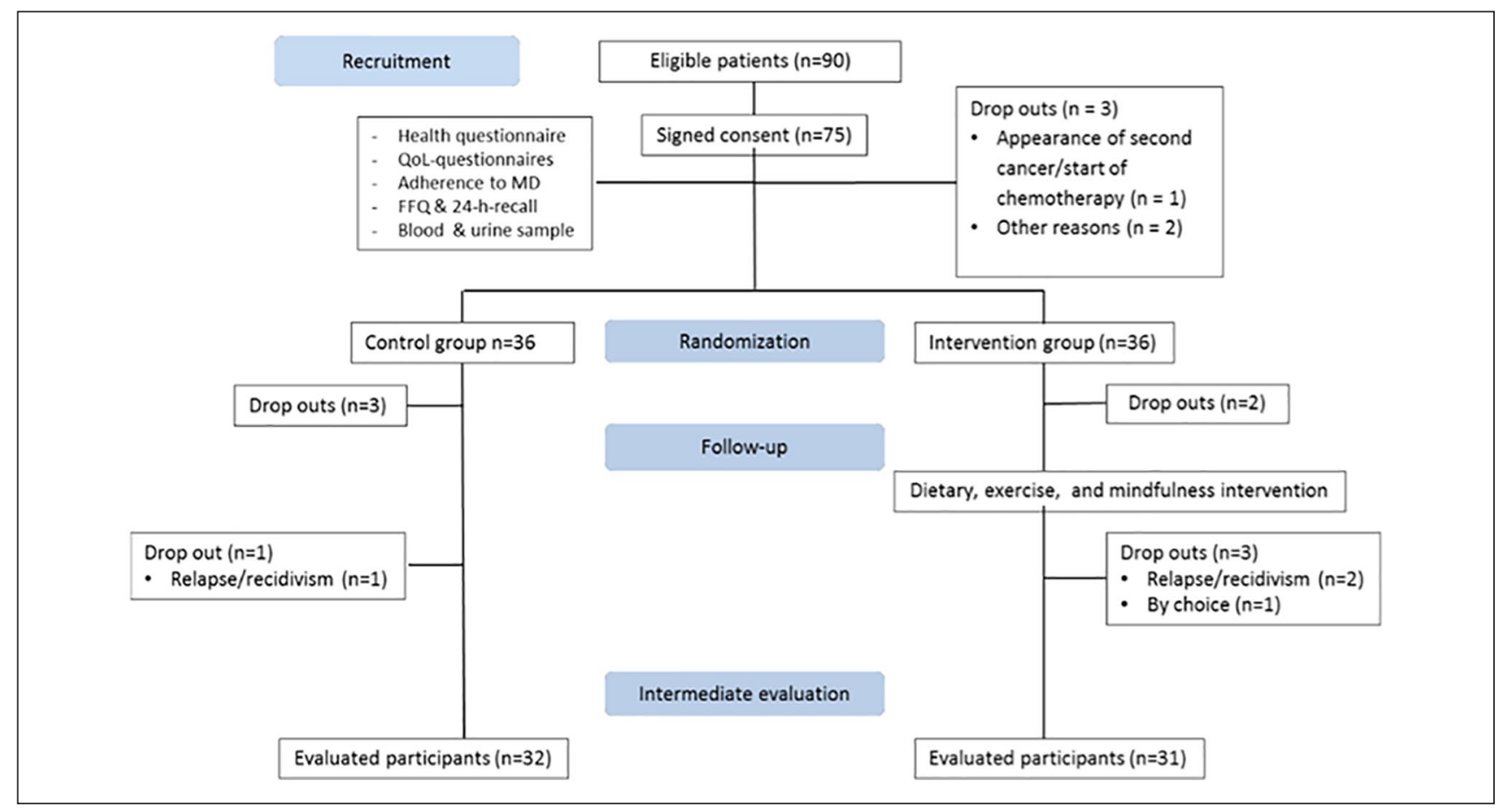

Figure I. The CONSORT flow diagram.

between before and after the intervention. The MannWhitney $U$ test was used to compare differences between $\mathrm{CG}$ and IG at the follow-up. $p<.05$ was considered significant in all tests.

\section{Results}

Between September 2015 and November 2015, 100 women attending the Oncology Mammary Unit of the HUVN who had completed their cancer treatment more than 12 months earlier were invited to participate in this study, and eligibility criteria were met by 90 of these. Out of the 75 who initially provided written consent to participation, 3 were lost to the baseline appointment ( 1 for second cancer diagnosis and 2 for other reasons), leaving a final sample of 72 women (36 in each group). Subsequently, 5 women in the IG and 4 in the $\mathrm{CG}$ were lost to the follow-up, leaving a final sample of 31 women in the IG and 32 in the CG (Figure 1).

\section{Baseline Characteristics of Study Population}

Table 1 displays the baseline sociodemographic data of the IG and CG, and Table 2 exhibits their dietary characteristics. No statistically significant between-group differences were found in any of these variables at baseline. The mean age was $48.33 \pm 7.72$ years in the $\mathrm{CG}$ and $51.32 \pm 10.15$ years in the IG. According to their body mass index values, $21.21 \%$ of the $\mathrm{CG}$ were overweight and $27.27 \%$ were obese; while $29.41 \%$ of the IG were overweight and $35.29 \%$ were obese. A normal weight was recorded in $51.52 \%$ of the CG and in $35.29 \%$ of the IG (35.29\%). Some physical activity was performed by $39.39 \%$ of the CG and by $55.88 \%$ of the IG (Table 1). In the CG, 51.52\% were ex-smokers, $30.30 \%$ had never smoked, and $18.18 \%$ were current smokers. In the IG, 29.41\% were ex-smokers, 50\% had never smoked, and $20.59 \%$ were current smokers. Alcoholic beverages were consumed by $81.8 \%$ of the CG and $82.4 \%$ of the IG (Table 1).

As shown in Table 2, a low MD adherence ( $<9$ points) was observed in $69.7 \%$ of the CG and $55.9 \%$ of the IG. The mean caloric intake was $1806.3 \mathrm{kcal}$ in the CG and 1714 $\mathrm{kcal}$ in the IG. In the $\mathrm{CG}$, the macronutrient distribution was $45.2 \%$ carbohydrates, $38.6 \%$ fat, $15.4 \%$ proteins, with a fiber intake of $17.2 \mathrm{~g}$. In the $\mathrm{IG}$, it was $46.8 \%$ carbohydrates, $36.0 \%$ fat, $16.5 \%$ proteins, with a fiber intake of $20.0 \mathrm{~g}$ (Table 2).

The breast tumor characteristics of the 2 groups are summarized in Table 3.

\section{Evaluation of Outcome Variables Pre-and Postintervention}

All 3 nutrition workshops were completed by $90 \%$ of the women in the IG, the exercise program was completed by $70 \%$, and the mindfulness intervention program by $59 \%$. Only 15 patients completed $\geq 75 \%$ of the whole program 
Table I. Baseline Sociodemographic Characteristics of the Study Population.

\begin{tabular}{|c|c|c|c|c|c|c|}
\hline \multirow[b]{2}{*}{ Variables } & \multicolumn{3}{|c|}{ Control Group $(n=33)$} & \multicolumn{3}{|c|}{ Intervention Group $(\mathrm{n}=34)$} \\
\hline & Mean (SD) & $\mathrm{P} 25$ & P75 & Mean (SD) & $\mathrm{P} 25$ & P75 \\
\hline \multirow[t]{2}{*}{ Age (years) } & $48.33 \pm 7.72$ & 41 & 54 & $51.32 \pm 10.15$ & 44 & 59.25 \\
\hline & $\mathrm{N}$ & \multicolumn{2}{|c|}{$\%$} & $\mathrm{~N}$ & \multicolumn{2}{|c|}{$\%$} \\
\hline \multicolumn{7}{|l|}{ BMI $\left(\mathrm{kg} / \mathrm{m}^{2}\right)$} \\
\hline Normal weight & 17 & \multicolumn{2}{|c|}{51.52} & 12 & \multicolumn{2}{|l|}{35.29} \\
\hline Overweight & 7 & \multicolumn{2}{|c|}{21.21} & 10 & \multicolumn{2}{|l|}{29.41} \\
\hline Obese & 9 & \multicolumn{2}{|c|}{27.27} & 12 & \multicolumn{2}{|l|}{35.29} \\
\hline \multicolumn{7}{|l|}{ Residence } \\
\hline Urban & 20 & \multicolumn{2}{|c|}{60.61} & 19 & \multicolumn{2}{|l|}{55.88} \\
\hline Rural & 13 & \multicolumn{2}{|c|}{39.39} & 15 & \multicolumn{2}{|l|}{44.12} \\
\hline \multicolumn{7}{|l|}{ Education } \\
\hline Up to primary school & 15 & \multicolumn{2}{|c|}{45.45} & 16 & \multicolumn{2}{|l|}{47.06} \\
\hline Secondary school & 7 & \multicolumn{2}{|c|}{21.21} & 6 & \multicolumn{2}{|l|}{17.65} \\
\hline University degree & 11 & \multicolumn{2}{|c|}{33.33} & 12 & \multicolumn{2}{|l|}{35.29} \\
\hline \multicolumn{7}{|l|}{ Income level } \\
\hline Low & 13 & 39.39 & & II & 32.35 & \\
\hline Middle & 20 & 60.61 & & 23 & 67.65 & \\
\hline Marital status & & & & & & \\
\hline Single & 4 & 12.12 & & 8 & 23.53 & \\
\hline With partner & 26 & 78.79 & & 23 & 67.65 & \\
\hline Divorced/widowed & 3 & 9.09 & & 3 & 8.82 & \\
\hline Employment/labor condit & & & & & & \\
\hline Unemployed & 9 & 27.27 & & 10 & 29.41 & \\
\hline Employed & 23 & 69.70 & & 23 & 67.65 & \\
\hline Retired & 1 & 3.03 & & 1 & 2.94 & \\
\hline Type of occupation & & & & & & \\
\hline Sedentary & 10 & 30.30 & & 7 & 20.59 & \\
\hline Standing & 17 & 51.52 & & 12 & 35.29 & \\
\hline Physical work & 6 & 18.18 & & 15 & 44.12 & \\
\hline Tobacco habit & & & & & & \\
\hline Never smoked & 10 & 30.30 & & 17 & 50.00 & \\
\hline Ex-smoker & 17 & 51.52 & & 10 & 29.41 & \\
\hline Current smoker & 6 & 18.18 & & 7 & 20.59 & \\
\hline Alcohol & & & & & & \\
\hline No & 6 & 18.2 & & 6 & 17.6 & \\
\hline Yes & 27 & 81.8 & & 28 & 82.4 & \\
\hline Physical activity & & & & & & \\
\hline No & 20 & 60.61 & & 15 & 44.12 & \\
\hline Yes & 13 & 39.39 & & 19 & 55.88 & \\
\hline
\end{tabular}

Abbreviations: SD, standard deviation; $\mathrm{P}$, percentile; BMI, body mass index.

(3 dietary workshops, 21 physical exercise classes, and 8 mindfulness sessions), mainly due to their entry into employment. The main outcome variables (including QoL and clinical data) were available for all study participants at both baseline and follow-up.

Quality of Life. In the IG, significant differences were found between baseline and the follow-up at 6 months in physical (73\% vs $87 \%[p=.001]$, role $83 \%$ vs $100 \%[p=.05])$, and social functioning (67\% vs $100 \%[p=.019])$, but not in cognitive or global health QoL status $(62.5 \%$ vs $67 \%[p=.59])$ or in symptoms, although there was a nonsignificant decrease in fatigue. In the $\mathrm{CG}$, a significant increase was observed in the frequency of dyspnea symptoms (from $0 \%$ to $16 \%$ $[p=.014]$ ) and fatigue (from $22 \%$ to $28 \%[p=.053]$; Table 4). In the comparison of data at the 6-month follow-up, the IG showed significantly greater improvements in physical and role functioning ( $p=.027$ and .028 , respectively), 
Table 2. Baseline Dietary Characteristics of the Study Population.

\begin{tabular}{|c|c|c|c|c|c|c|c|}
\hline & \multicolumn{3}{|c|}{ Control Group $(\mathrm{n}=33)$} & \multicolumn{4}{|c|}{ Intervention Group $(n=34)$} \\
\hline & Mean (SD) & $\mathrm{P} 25$ & P75 & Mean (SD) & $\mathrm{P} 25$ & & P75 \\
\hline Total energy (kcal) & $1806.3 \pm 626.8$ & 1308.8 & 2161.8 & $17 \mid 4.0 \pm 533.6$ & 1389.0 & & 1976.1 \\
\hline Carbohydrates (\%) & $45.2 \pm 11.3$ & 38.2 & 49.4 & $46.8 \pm 7.4$ & 43.1 & & 51.8 \\
\hline Fat $(\%)$ & $38.6 \pm 10.7$ & 32.0 & 46.9 & $36.0 \pm 5.8$ & 31.9 & & 39.0 \\
\hline Proteins (\%) & $15.4 \pm 5.3$ & 11.5 & 18.3 & $16.5 \pm 4.2$ & 13.5 & & 19.0 \\
\hline \multirow[t]{3}{*}{ Dietary fiber $(\mathrm{g})$} & $17.2 \pm 6.0$ & 13.7 & 21.5 & $20.0 \pm 8.7$ & 14.8 & & 24.5 \\
\hline & \multicolumn{3}{|c|}{ Control Group $(\mathrm{n}=33)$} & \multicolumn{4}{|c|}{ Intervention Group $\left(\mathrm{n}=34^{\mathrm{a}}\right)$} \\
\hline & $\mathrm{N}$ & & & $\mathrm{n}$ & & $\%$ & \\
\hline \multicolumn{8}{|l|}{ Mediterranean diet ${ }^{\mathrm{a}, \mathrm{b}}$} \\
\hline Low adherence & 23 & \multicolumn{2}{|c|}{69.7} & 19 & \multicolumn{3}{|c|}{55.9} \\
\hline Good adherence & 10 & \multicolumn{2}{|c|}{30.3} & 14 & \multicolumn{3}{|c|}{41.2} \\
\hline
\end{tabular}

Abbreviations: SD, standard deviation; $\mathrm{P}$, percentile.

a One questionnaire of Adherence to Mediterranean diet was not evaluated because of the participant's complete lack of olfaction and taste after breast cancer treatment.

bow adherence ( $<9$ points); good adherence ( $\geq 9$ points).

Table 3. Baseline Clinical Characteristics of the Study Population

\begin{tabular}{|c|c|c|c|c|}
\hline & \multicolumn{2}{|c|}{$\begin{array}{l}\text { Control Group (n } \\
\quad=33 \text { ) }\end{array}$} & \multicolumn{2}{|c|}{$\begin{array}{l}\text { Intervention Group } \\
\qquad(\mathrm{n}=34)\end{array}$} \\
\hline & $\mathrm{N}$ & $\%$ & $\mathrm{n}$ & $\%$ \\
\hline \multicolumn{5}{|c|}{ Family history of breast cancer } \\
\hline No & $16^{\mathrm{b}}$ & 50.00 & $23^{b}$ & 69.70 \\
\hline Yes & $16^{\mathrm{b}}$ & 50.00 & $10^{\mathrm{b}}$ & 30.30 \\
\hline \multicolumn{5}{|c|}{ Family history of other cancers } \\
\hline No & 13 & 39.39 & 13 & 38.23 \\
\hline Yes & 20 & 60.61 & 21 & 61.77 \\
\hline \multicolumn{5}{|l|}{ ER } \\
\hline Positive & $30^{\mathrm{b}}$ & 93.75 & $26^{\mathrm{b}}$ & 78.79 \\
\hline Negative & $2^{\mathrm{b}}$ & 6.25 & $7^{\mathrm{b}}$ & 21.21 \\
\hline \multicolumn{5}{|l|}{ HER2 } \\
\hline Positive & $5^{b}$ & 15.63 & $7^{\mathrm{b}}$ & 21.21 \\
\hline Negative & $27^{b}$ & 84.37 & $26^{\mathrm{b}}$ & 78.79 \\
\hline \multicolumn{5}{|l|}{ Stage } \\
\hline IIA & 13 & 39.39 & 19 & 55.88 \\
\hline IIB & 19 & 57.57 & 13 & 38.23 \\
\hline Unknown & 1 & 3.03 & 2 & 5.88 \\
\hline \multicolumn{5}{|c|}{ Hormone therapy } \\
\hline No & 5 & 15.15 & 4 & 11.76 \\
\hline Yes & 28 & 84.85 & 30 & 88.24 \\
\hline
\end{tabular}

Abbreviations: ER, estrogen receptor; HER-2, human epidermal growth factor receptor 2 .

an some groups, the sum of participants differs from the total number because information was missing from medical records.

bNo data for one woman.

while the CG showed a close-to-significant increase in dyspnea symptoms in comparison with the IG $(p=.066$; Table 5).
Weight Change and MD Adherence. In the IG, a significant increase between baseline and 6-month follow-up was observed in mean MD adherence score (from 7 to 10 points, $p=.008)$ and in the percentage of women with good MD adherence ( $>9$ points; from $44 \%$ to $73 \%$ [ $p=.035]$; Table 4 ). At the 6-month follow-up, a significant difference between IG and CG was found in the percentage with good MD adherence $(73 \%$ of IG vs $22 \%$ of CG, $p<.001)$, in the mean MD adherence score ( 8 for $\mathrm{CG}$ and 10 for $\mathrm{IG}$, $p<.001$; Table 4), in weight gain (gain of $550 \mathrm{~g}$ for CG vs loss of $720 \mathrm{~g}$ for IG, $p=.05$ ), and in body mass index $(p=.04$; Table 5).

Clinical Measurements. Between baseline and the end of the follow-up, total cholesterol, low-density lipoprotein, and high-density lipoprotein were significantly reduced in both the IG and $\mathrm{CG}$, while triglycerides were significantly reduced in the IG and significantly increased in the CG; cancer antigen 15.3 was also significantly increased in the CG (Table 4). At the end of the follow-up, mean triglyceride levels were decreased in the IG $(-9.6 \mathrm{mg} / \mathrm{dL})$ and increased in the CG $(+21.5 \mathrm{mg} / \mathrm{dL})$, a significant between-group difference $(p<.001$; Table 5$)$. Low-density lipoprotein and high-density lipoprotein cholesterol levels were also improved in the IG in comparison to the CG (Table 5).

\section{Discussion}

The integrative intervention program proposed in this study proved to be an effective approach to improve the QoL of $\mathrm{BC}$ survivors, although the effect was only moderate after the established follow-up period (6 months). It also enhanced healthy lifestyle habits, significantly increasing adherence to the MD, and weight control. 
Table 4. Changes in Functional and Symptom Scales of QLQ-C30, Adherence to Mediterranean Diet, and Clinical Markers ${ }^{\mathrm{a}}$.

\begin{tabular}{|c|c|c|c|c|c|c|}
\hline & \multicolumn{3}{|c|}{ Control Group (n=32) } & \multicolumn{3}{|c|}{ Intervention Group $(n=3 I)$} \\
\hline & Baseline & End Follow-up ${ }^{\mathrm{b}}$ & $p$ & Baseline & End Follow-up ${ }^{\mathrm{b}}$ & $p$ \\
\hline \multicolumn{7}{|l|}{ Functional scales } \\
\hline Physical functioning & 80 (73.3-9।.7) & $80(61.7-93.3)$ & .992 & $73.3(58.3-93.3)$ & $86.7(73.3-93.3)$ & .001 \\
\hline Role functioning & $91.7(66.7-100)$ & $91.7(33.3-100)$ & .071 & $83.3(50-100)$ & $100(83.3-100)$ & .05 \\
\hline Cognitive functioning & $66.7(37.5-100)$ & $66.7(33.3-83.3)$ & .270 & $66.7(45.8-83.3)$ & $83.3(33.3-83.3)$ & .894 \\
\hline Emotional functioning & $66.7(33.3-91.7)$ & $75(41.66-83.33)$ & .095 & $66.7(47.9-85.4)$ & 75 (66.7-9I.7) & .100 \\
\hline Social functioning & $83.3(50-100)$ & $91.66(50-100)$ & .423 & $66.7(45.8-100)$ & $100(83.3-100)$ & .019 \\
\hline Global health status & $62.5(41.7-83.3)$ & $66.7(43.7-83.3)$ & .662 & $62.5(50-83.3)$ & $66.7(66.7-83.3)$ & .589 \\
\hline \multicolumn{7}{|l|}{ Symptom and problem scales } \\
\hline Fatigue & $22.2(0-4 \mid .7)$ & $27.8(2.8-63.9)$ & .053 & $33.3(0-55.5)$ & $22.2(\mathrm{I} I .1-44.4)$ & .693 \\
\hline Pain & $33.3(16.7-66.7)$ & $41.7(20.8-66.7)$ & .471 & $33.3(16.7-66.7)$ & $33.3(0-66.7)$ & .759 \\
\hline Dyspnea & $0(0-33.3)$ & $16.7(0-66.7)$ & .014 & $0(0-33.3)$ & $0(0-33.3)$ & .635 \\
\hline Insomnia & $33.3(8.3-66.7)$ & $66.7(0-66.7)$ & .545 & $33.3(0-66.7)$ & $33.3(33.3-66.7)$ & .019 \\
\hline \multicolumn{7}{|l|}{ Adherence to MD } \\
\hline MD score & $7.5(6-9)$ & $8.0(7-8)$ & .292 & $7.0(6-10)$ & $10(8-11)$ & .008 \\
\hline \multicolumn{7}{|l|}{ Good adherence MD } \\
\hline n (\%) & $10(31 \%)$ & 7 (22\%) & .375 & 14 (44\%) & $24(73 \%)$ & .035 \\
\hline BMI $\left(\mathrm{kg} / \mathrm{m}^{2}\right)$ & 24.6 & 25.5 & .260 & 26.4 & 26.7 & .270 \\
\hline \multicolumn{7}{|l|}{ Clinical markers } \\
\hline Total cholesterol (mg/dL) & $206(|8|-|2|)$ & $188(|72-2| 7)$ & 0.009 & $196(169-245)$ & I8I (I63.5-2I7) & .038 \\
\hline $\mathrm{LDL}(\mathrm{mg} / \mathrm{dL})$ & I 34 (| 28-|44) & $126(|16-| 4 \mid)$ & 0.049 & 161 (93-179) & II 4 (9|-|52) & .01 \\
\hline $\mathrm{HDL}(\mathrm{mg} / \mathrm{dL})$ & $68(57-73)$ & $59(54-62)$ & 0.038 & $64(48-72)$ & $57(55-6 I)$ & .046 \\
\hline Triglycerides (mg/dL) & $85(72-102)$ & III (84- I35) & $<0.001$ & $102(76-130)$ & $90(76-I 10)$ & .077 \\
\hline Ca I5.3 & $9.6(7.4-12.9)$ & I $2.3(8.8-\mid 4.5)$ & 0.044 & $10(9-14)$ & $10(8-12)$ & 1 \\
\hline
\end{tabular}

Abbreviations: QOL-30, quality of life test for oncology patients; MD, Mediterranean diet; BMI, body mass index; LDL, low-density lipoprotein; HDL, high-density lipoprotein; Ca I5.3, cancer antigen I5.3.

${ }^{a}$ Variables are expressed as medians (IQR). $p$ values for comparison of the mean change in variables among women inside the control or intervention groups between baseline and follow-up were obtained using the Mann-Whitney $U$ test.

${ }^{b}$ End follow-up: 6 months after intervention program.

It has previously been reported that the functions, symptoms, and complications of $\mathrm{BC}$ patients can be improved by integrative programs that promote a healthy lifestyle, including diet, physical activity, and/or mindfulness..$^{27,28}$ Cancer survivors are known to face multiple physical and emotional challenges. ${ }^{5}$ It has been observed that women who survive $\mathrm{BC}$ experience emotional difficulties that can affect their QoL and increase the risk of complications. ${ }^{13,14,29}$ In the present study, some of the most frequent and persistent problems of $\mathrm{BC}$ survivors (impaired QoL, fatigue, and physical deconditioning) were improved at 6 months after the integrative intervention, with a significant increase in physical and role functioning ( $p=.027$ and .028 , respectively). At the end of the follow-up, fatigue, which has been related to physical functionality in cancer patients, ${ }^{30}$ was less frequently reported by women who had participated in the intervention program than by those who had not. There was also a tendency for dyspnea to be more frequent in the CG than in the IG $(p=.066)$.

The "Continuous Update Project-CUP" program of the WCRF/AICR (World Cancer Research Fund and the
American Institute for Cancer Research) ${ }^{31}$ described a positive relationship between certain lifestyle characteristics and improved survival in patients with BC. In this line, the wide European prospective cohort study found that adherence to WCRF/AICR recommendations on diet, physical activity, and body fatness was inversely related to all studied causes of death, including death from cancer; and a decrease in adiposity and an increase in plant-based food consumption were the factors most strongly associated with a reduced risk of death. ${ }^{7}$

The present results demonstrate that this type of integrative intervention program can promote a healthy lifestyle, including adherence to the MD, measured using a simple scale of 14 items related to the key characteristics of this dietary pattern. ${ }^{23,24}$ Adherence to the MD was significantly greater in the women who received the program than in the controls after 6 months of follow-up, and this was related to their weight loss. However, a longer follow-up is required to verify the maintenance of $\mathrm{MD}$ adherence over the longer term.

Before the intervention, a majority of the women were overweight or obese, which has been associated with a 
Table 5. CG Versus IG for Mean Change in Health Variables.

\begin{tabular}{|c|c|c|c|c|c|c|c|}
\hline & \multicolumn{3}{|c|}{$\mathrm{CG}, \mathrm{n}=32$} & \multicolumn{3}{|c|}{$\mid \mathrm{G}, \mathrm{n}=3 \mathrm{I}$} & \multirow{2}{*}{$\begin{array}{c}\text { IG Versus } \\
\text { CG } \\
p^{\mathrm{a}}\end{array}$} \\
\hline & $\begin{array}{l}\text { CG Baseline, } \\
\text { Mean (SD) }\end{array}$ & $\begin{array}{c}\text { CG } 6 \text { Months, } \\
\text { Mean (SD) }\end{array}$ & $\begin{array}{c}\text { Change, Mean } \\
\text { (SD) }\end{array}$ & $\begin{array}{l}\text { IG Baseline, } \\
\text { Mean (SD) }\end{array}$ & $\begin{array}{l}\text { IG } 6 \text { Months, } \\
\text { Mean (SD) }\end{array}$ & $\begin{array}{c}\text { Change, Mean } \\
\text { (SD) }\end{array}$ & \\
\hline Physical functioning & $79.2(15.7)$ & $78.3(18.9)$ & $-0.89(17.9)$ & $75.4(19.5)$ & $85.0(14.1)$ & $9.6(14.4)$ & .027 \\
\hline Social functioning & $73.4(28.4)$ & $78.7(28.5)$ & $5.2(37.3)$ & $69.4(29.8)$ & $83.3(24.7)$ & $14.0(32.8)$ & .429 \\
\hline Role functioning & $81.3(22.7)$ & $71.9(32.1)$ & $-9.4(29.0)$ & $77.4(25.3)$ & $86.6(21.3)$ & $9.2(28.5)$ & .028 \\
\hline $\begin{array}{l}\text { Cognitive } \\
\text { functioning }\end{array}$ & $66.7(33.3)$ & $58.9(31.7)$ & $-7.8(34.1)$ & $66.1(29.7)$ & $66.1(26.4)$ & $0.0(24.0)$ & .330 \\
\hline Global health status & $62.2(26.3)$ & 64.I (22.7) & I.82 (28.I) & $66.9(23.2)$ & $69.4(20.2)$ & $2.42(18.2)$ & .928 \\
\hline Fatigue & $26.4(27.5)$ & $34.7(32.3)$ & $8.3(21.9)$ & $30.1(28.6)$ & $28.3(19.4)$ & $-1.8(23.9)$ & .096 \\
\hline Pain & $39.6(28.3)$ & $44.8(30.7)$ & $5.2(32.4)$ & $37.1(29.1)$ & $35.5(28.1)$ & $-1.6 I(25.2)$ & .520 \\
\hline Dyspnea & $17.7(26.8)$ & $31.3(35.9)$ & I $3.5(29.2)$ & $17.2(25.6)$ & I5.I (25.6) & $-2.2(27.1)$ & .066 \\
\hline Insomnia & $48.0(36.9)$ & $51.0(36.9)$ & $3.1(32.1)$ & $33.3(32.2)$ & $48.4(34.3)$ & I5.I (32.0) & .102 \\
\hline Emotional & $60.9(29.2)$ & $66.7(26.5)$ & $5.73(24.9)$ & $66.4(26.7)$ & $73.4(24.9)$ & $6.99(31.0)$ & .950 \\
\hline MD score & $7.4(2.2)$ & $7.8(1.7)$ & $0.31(1.73)$ & $8.1(2.9)$ & $9.7(1.7)$ & $1.57(2.6)$ & $.05 I^{b}$ \\
\hline $\begin{array}{l}\text { High MD } \\
\text { adherence n (\%) }\end{array}$ & $10(31.3)$ & 7 (21.9) & $-9.4 \%$ & $13(4 \mid .9)$ & $24(77.4)$ & $+35.5 \%$ & $.02^{\mathrm{b}}$ \\
\hline BMI $\left(\mathrm{kg} / \mathrm{m}^{2}\right)$ & $26.8(6.0)$ & $27.0(6.2)$ & $0.22(1.05)$ & $28.0(5.0)$ & $27.7(4.9)$ & $-0.29(0.95)$ & .043 \\
\hline Weight (kg) & $68.9(14.7)$ & $69.5(15.0)$ & $0.55(2.70)$ & $69.8(12.0)$ & $69.0(11.7)$ & $-0.72(2.42)$ & .052 \\
\hline Glucose (mg/dL) & $84.5(10)$ & 86.9 (1I.7) & $1.85(9.4)$ & $83.2(12.7)$ & $87.4(14.1)$ & $4.2(18.8)$ & .905 \\
\hline TG (mg/dL) & 91.4 (31.7) & $111.9(55.3)$ & $21.5(32.3)$ & $106.8(40.6)$ & $98.3(36.8)$ & $-9.6(28.1)$ & $<.001$ \\
\hline TC (mg/dL) & $204.9(29.6)$ & $191.9(30.3)$ & $-13.5(24.5)$ & $209.4(44.3)$ & $190.5(34.8)$ & $-12.1(26.2)$ & .670 \\
\hline HDL (mg/dL) & $65.9(8.5)$ & $59.3(8.4)$ & $-7.1(8.4)$ & $61.2(13.2)$ & $62.1(14.1)$ & $0.92(6.3)$ & .022 \\
\hline LDL (mg/dL) & 133 (17.9) & $122(26.9)$ & $-2.8(24.5)$ & $195(226)$ & I I 7.2 (3।.5) & $-\mid 8.6(2 \mid .6)$ & .113 \\
\hline CA I5.3 (U/mL) & $13.0(15.6)$ & I3.I (14.9) & $-0.14(1.61)$ & $11.5(4.3)$ & II.7 (4.9) & $0.55(3.5)$ & .684 \\
\hline
\end{tabular}

Abbreviations: CG, control group; IG, intervention group; SD, standard deviation; MD, Mediterranean diet; BMI, body mass index; TG, triglyceride; TC, total cholesterol; HDL, high-density lipoprotein; LDL, low-density lipoprotein; CA, cancer antigen.

Variables are expressed as means (SD).

Bold values shows the statistical significance.

${ }^{a} p$ values for comparison of the mean change in health variables between control groups and intervention groups were obtained using Mann-Whitney $U$ test. ${ }^{\mathrm{b}} \mathrm{p}$ values obtained using Chi-squared test.

higher risk of $\mathrm{BC}$ and a worse prognosis. ${ }^{32}$ At 6 months after the intervention, the weight of the women in the $\mathrm{CG}$ had increased versus baseline by a mean of $0.55 \mathrm{~kg}$, whereas the weight of those in the IG had decreased by a mean of $0.72 \mathrm{~kg}(p=.05)$. An even greater weight loss was observed in the 15 women who attended all 3 dietary workshops (data not shown). A postdiagnostic weight gain of up to 8 $\mathrm{kg}$ has been reported in $68 \%$ of $\mathrm{BC}$ patients at 3 years postdiagnosis. ${ }^{33}$ Besides being a risk factor for both pre- and postmenopausal BC and its recurrence, being overweight is significantly associated with mortality for all causes, including BC. ${ }^{6}$ Specifically, the risk of mortality from BC has been estimated to increase by $8 \%$ to $29 \%$ for each body mass index unit increase in pre- and postmenopausal BC survivors. ${ }^{34,35}$ Many studies have shown that BC survivors can benefit from interventions to improve diet and exercise, possibly due to a reduction in weight ${ }^{36}$ and body fat. ${ }^{28}$

Multiple cellular and molecular pathways are implicated in the link between adiposity and the risk and prognosis of cancer. Obesity produces systemic changes in various metabolic and endocrine pathways that can lead to hyperinsulinemia, increased estradiol levels, and a state of chronic inflammation, among other systemic effects. ${ }^{6}$

Importantly, most of these systemic effects can promote multiple hallmarks of cancer, including sustained proliferative signaling, resistance to cell death, activation of invasion/ metastasis, induction of angiogenesis, genome instability/ mutation, and inflammation. For example, in the case of $\mathrm{BC}$ in postmenopausal women, an increase in adiposity is related to greater aromatase activity and, therefore, to an increase in the production of estrogen, which can stimulate the proliferation of breast tissue of hormonally dependent tumors, favoring the development of BC. ${ }^{37}$

Regular physical exercise is a fundamental pillar of cancer prevention, and multiple mechanisms underlie its protective effects. ${ }^{38-42}$ Thus, it decreases insulin resistance, improves immune function, reduces hormonal production, counteracts free radicals, and diminishes leptin, among other actions. ${ }^{12,43}$ It has been reported that physical activity contributes to increasing survival rates after $\mathrm{BC}$ remission and to preventing relapse in $\mathrm{BC}$ patients. ${ }^{43} \mathrm{It}$ is also important to take into account its preventive effect against 
obesity-associated comorbidities such as diabetes, cardiovascular disease, and hypertension, which increase the risk of relapse and cancer death as well as non-cancerspecific deaths. ${ }^{44}$ Accordingly, regular exercise not only reduces the risk of recurrence and metastases in patients with $\mathrm{BC}$, but also enhances their weight control and overall health. ${ }^{45}$

MBSR programs have been reported to significantly improve the perceived stress, depression, anxiety, ${ }_{15,46}^{15}$ quality of sleep ${ }^{17}$ fear, ${ }^{18}$ and mental health ${ }^{46}$ of $\mathrm{BC}$ survivors, increasing their QoL. ${ }^{17,18}$ The women participating in the present program showed no statistically significant changes in the emotional domain, but achieved a significant improvement $(p=.019)$ in social functioning.

Different international scientific societies have published recommendations for a healthy lifestyle, mainly related to diet and physical exercise; however, they have not yet been integrated in oncology rehabilitation units for cancer survivors. The present study contributes to increasing evidence that an integrative approach can improve the QoL of BC survivors, especially in relation to their physical, social, and functional well-being, and can help to reduce their symptoms and associated complications.

\section{Strengths and Limitations}

Strengths of this study include the population of high-risk $\mathrm{BC}$ survivors with elevated high rates of inactivity and obesity; the targeting of early survivorship; the randomized controlled trial design; and the wide range of study outcomes, including both subjective and objective measures. Limitations include the relatively low adherence rate to the intervention, with only 15 patients completing $>75 \%$ of program sessions. Work scheduling problems meant that the majority of the women could not attend all physical exercise and mindfulness sessions. The small sample size limits the reliability of the estimates and the capacity to detect subtle effects.

\section{Conclusion}

The results of this study indicate that an integrative intervention program on diet, physical activity, and mindfulness has positive effects on the QoL (physical, role, and social function) of $\mathrm{BC}$ patients and promotes healthy lifestyle habits, weight loss, and an improved serum lipid profile.

The elevated incidence and prevalence of $\mathrm{BC}$ has increased research interest in complementary treatments for cancer survivors. The present findings support the implementation of complementary interventions that combine diet, exercise, and stress-reduction techniques. This type of integrative program may also help prevent $\mathrm{BC}$ recurrence and the development of secondary tumors. Further studies are required to confirm the strength of scientific evidence for these novel complementary interventions. Greater public health efforts are warranted to implement integrative oncology interventions that promote and maintain a healthy lifestyle in $\mathrm{BC}$ survivors.

\section{Author's Note}

Lucas Jurado is also affiliated with PROmoting FITness and Health through physical activity (PROFITH) Research Group and Sport and Health Joint University Institute (iMUDS), Granada, Spain. Manuel Arroyo-Morales is also affiliated with Support Unit for Oncology Patients (UAPO-“Cuídate")and Sport and Health Joint University Institute (iMUDS), University of Granada, Granada, Spain.

\section{Declaration of Conflicting Interests}

The author(s) declared no potential conflicts of interest with respect to the research, authorship, and/or publication of this article.

\section{Funding}

The author(s) received no financial support for the research, authorship, and/or publication of this article.

\section{Trial Registration}

This trial was registered with ClinicalTrials.gov (NCT04150484).

\section{ORCID iD}

Julia Ruiz-Vozmediano iD https://orcid.org/0000-0002-9516-8046

\section{References}

1. Forman D, Bray F, Brewster DH, et al. Cancer Incidence in Five Continents, Volume X. Lyon, France: International Agency for Research on Cancer; 2014.

2. Anand P, Kunnumakkara AB, Sundaram C, et al. Cancer is a preventable disease that requires major lifestyle changes. Pharm Res. 2008;25:2097-2116.

3. International Agency for Research on Cancer. European code against cancer. http://cancer-code-europe.iarc.fr/index.php/ en/. Accessed May 17, 2019.

4. Bray F, Ferlay J, Soerjomataram I, Siegel RL, Torre LA, Jemal A. Global cancer statistics 2018: GLOBOCAN estimates of incidence and mortality worldwide for 36 cancers in 185 countries. CA Cancer J Clin. 2018;68:394-424.

5. Menning S, de Ruiter MB, Kieffer JM, et al. Cognitive impairment in a subset of breast cancer patients after systemic therapy-results from a longitudinal study. J Pain Symptom Manage. 2016;52:560-569.e1.

6. World Cancer Research Fund International/American Institute for Cancer Research. Continuous Update Project Report. Diet, nutrition, physical activity, and breast cancer survivors. www. wcrf.org/sites/default/files/Breast-Cancer-Survivors-2014Report.pdf. Published 2014. Accessed May 17, 2019.

7. Vergnaud AC, Romaguera D, Peeters PH, et al. Adherence to the World Cancer Research Fund/American Institute for Cancer Research guidelines and risk of death in Europe: results from the European Prospective Investigation into Nutrition and Cancer cohort study1, 4. Am J Clin Nutr. 2013; 97:1107-1120. 
8. Castelló A, Pollán M, Buijsse B, et al. Spanish Mediterranean diet and other dietary patterns and breast cancer risk: casecontrol EpiGEICAM study. Br J Cancer. 2014;111:1454-1462.

9. Jung S, Spiegelman D, Baglietto L, et al. Fruit and vegetable intake and risk of breast cancer by hormone receptor status. $J$ Natl Cancer Inst. 2013;105:219-236.

10. Izano MA, Fung TT, Chiuve SS, Hu FB, Holmes MD. Are diet quality scores after breast cancer diagnosis associated with improved breast cancer survival? Nutr Cancer. 2013;65:820826.

11. Ibrahim EM, Al-Homaidh A. Physical activity and survival after breast cancer diagnosis: meta-analysis of published studies. Med Oncol. 2011;28:753-765.

12. de Boer MC, Wörner EA, Verlaan D, van Leeuwen PAM. The mechanisms and effects of physical activity on breast cancer. Clin Breast Cancer. 2017;17:272-278.

13. Carayol M, Ninot G, Senesse P, et al. Short- and long-term impact of adapted physical activity and diet counseling during adjuvant breast cancer therapy: the "APAD1" randomized controlled trial. BMC Cancer. 2019;19:737.

14. Greenlee H, DuPont-Reyes MJ, Balneaves LG, et al. Clinical practice guidelines on the evidence-based use of integrative therapies during and after breast cancer treatment. CA Cancer J Clin. 2017;67:194-232.

15. Zhang MF, Wen YS, Liu WY, Peng LF, Wu XD, Liu QW. Effectiveness of mindfulness-based therapy for reducing anxiety and depression in patients with cancer. A meta-analysis. Medicine (Baltimore). 2015;94:e0897-0.

16. Kiecolt-Glaser JK, Bennett JM, Andridge R, et al. Yoga's impact on inflammation, mood, and fatigue in breast cancer survivors: a randomized controlled trial. J Clin Oncol. 2014;32:1040-1049.

17. Speca M, Carlson LE, Goodey E, Angen M. A randomized, wait-list controlled clinical trial: the effect of a mindfulness meditation-based stress reduction program on mood and symptoms of stress in cancer outpatients. Psychosom Med. 2000;62:613-622.

18. Carlson LE, Speca M, Patel KD, Goodey E. Mindfulness-based stress reduction in relation to quality of life, mood, symptoms of stress and levels of cortisol, dehydroepiandrosterone sulfate (DHEA) and melatonin in breast and prostate cancer outpatients. Psychoneuroendocrinology. 2004;29:448-474.

19. Lengacher CA, Johnson-Mallard V, Post-White J, et al. Randomized controlled trial of mindfulness-based stress reduction (MBSR) for survivors of breast cancer. Psychooncology. 2009; 18:1261-1272.

20. Fayers PM, Aaronson NK, Bjordal K, Groenvold M, Curran D, Bottomley A. The EORTC QLQ-C30 Scoring Manual (3rd Edition). Brussels, Belgium: European Organization for Research and Treatment of Cancer; 2001.

21. Husson O, de Rooij BH, Kieffer J, et al. The EORTC QLQ-C30 Summary score as prognostic factor for survival of patients with cancer in the "real-world": results from the population-based PROFILES registry. Oncologist. 2020;25:e722-e732.

22. Vioque J, Navarrete-Muñoz EM, Gimenez-Monzó D, et al. Reproducibility and validity of a food frequency questionnaire among pregnant women in a Mediterranean area. Nutr J. 2013;12:26.
23. Schröder H, Fitó M, Estruch R, et al. A short screener is valid for assessing Mediterranean diet adherence among older Spanish men and women. J Nutr. 2011;141:1140-1145.

24. Trichopoulou A, Costacou T, Bamia C, Trichopoulos D. Adherence to a Mediterranean diet and survival in a Greek population. N Engl J Med. 2003;348:2599-2608.

25. Davidson RJ, Kabat-Zinn J, Schumacher J, et al. Alterations in brain and immune function produced by mindfulness meditation. Psychosom Med. 2003;65:564-570.

26. Eyigor S, Karapolat H, Yesil H, Uslu R, Durmaz B. Effects of Pilates exercises on functional capacity, flexibility, fatigue, depression and quality of life in female breast cancer patients: a randomized controlled study. Eur J Phys Rehabil Med. 2010;46:481-487.

27. Scott E, Daley AJ, Doll H, et al. Effects of an exercise and hypocaloric healthy eating program on biomarkers associated with long-term prognosis after early-stage breast cancer: a randomized controlled trial. Cancer Causes Control. 2013;24:181-191.

28. Swisher AK, Abraham J, Bonner D, et al. Exercise and dietary advice intervention for survivors of triple-negative breast cancer: effects on body fat, physical function, quality of life, and adipokine profile. Support Care Cancer. 2015;23:2995-3003.

29. López VAQ, López KJD, Juvera GC. Interventions to improve healthy lifestyles and their effects on psychological variables among breast cancer survivors: a systematic review [in Spanish]. Nutr Hosp. 2018;35:979-992.

30. Meneses-Echávez JF, González-Jiménez E, Ramírez-Vélez $R$. Effects of supervised exercise on cancer-related fatigue in breast cancer survivors: a systematic review and meta-analysis. BMC Cancer. 2015;15:77.

31. WCRF/AICR, Continuous Update Project Report. Breast Cancer, 2010 Report: food, nutrition, physical activity, and the prevention of breast cancer. https:/www.wcrf.org/sites/ default/files/Breast-Cancer-2010-Report.pdf. Accessed April 28, 2020.

32. Majed B, Moreau T, Asselain B; Curie Institute Breast Cancer Group. Overweight, obesity and breast cancer prognosis: optimal body size indicator cut-points. Breast Cancer Res Treat. 2009;115:193-203.

33. San Felipe MJR, Martínez AA, Manuel-y-Keenoy B. Influence of body weight on the prognosis of breast cancer survivors; nutritional approach after diagnosis [in Spanish]. Nutr Hosp. 2013;28:1829-1841.

34. Reeves GK, Pirie K, Beral V, Green J, Spencer E, Bull D; Million Women Study Collaboration. Cancer incidence and mortality in relation to body mass index in the Million Women Study: cohort study. BMJ. 2007;335:1134.

35. Chan DS, Norat T. Obesity and breast cancer: not only a risk factor of the disease. Curr Treat Options Oncol. 2015;16:22.

36. Travier N, Fonseca-Nunes A, Javierre C, et al. Effect of a diet and physical activity intervention on body weight and nutritional patterns in overweight and obese breast cancer survivors. Med Oncol. 2014;31:783.

37. Russo J, Balogh GA, Chen J, et al. The concept of stem cell in the mammary gland and its implication in morphogenesis, cancer and prevention. Front Biosci. 2006;11:151-172.

38. Friedenreich CM, Gregory J, Kopciuk KA, Mackey JR, Courneya KS. Prospective cohort study of lifetime physical 
activity and breast cancer survival. Int J Cancer. 2009;124: 1954-1962.

39. Emaus A, Veierød MB, Tretli S, et al. Metabolic profile, physical activity, and mortality in breast cancer patients. Breast Cancer Res Treat. 2010;121:651-660.

40. Sternfeld B, Weltzien E, Quesenberry CP Jr, et al. Physical activity and risk of recurrence and mortality in breast cancer survivors: findings from the LACE study. Cancer Epidemiol Biomarkers Prev. 2009;18:87-95.

41. Chen X, Lu W, Zheng W, et al. Exercise after diagnosis of breast cancer in association with survival. Cancer Prev Res (Phila). 2011;4:1409-1418.

42. Holmes MD, Chen WY, Feskanich D, Kroenke CH, Colditz GA. Physical activity and survival after breast cancer diagnosis. JAMA. 2005;293:2479-2486.
43. Ballard-Barbash R, Friedenreich CM, Courneya KS, Siddiqi SM, McTiernan A, Alfano CM. Physical activity, biomarkers and disease outcomes in cancer survivors: a systematic review. J Natl Cancer Inst. 2012;104:815-840.

44. Lynch BM, Dunstan DW, Vallance JK, Owen N. Don't take cancer sitting down. A new survivorship research agenda. Cancer. 2013;119:1928-1935.

45. Lahart IM, Metsios GS, Nevill AM, Carmichael AR. Physical activity, risk of death and recurrence in breast cancer survivors: a systematic review and meta-analysis of epidemiological studies. Acta Oncol. 2015;54:635-654.

46. Zainal NZ, Booth S, Huppert FA. The efficacy of mindfulness-based stress reduction on mental health of breast cancer patients: a meta-analysis. Psychooncology. 2013;22: 1457-1465. 